\section{Language steamrollers?}

Jared Diamond's tabulation ${ }^{1}$ of the number and degree of dissimilarity between the world's extant languages shows how unevenly this kind of human variation is distributed geographically. This is perhaps the greatest mystery of historical linguistics. If early Holocene linguistic upheavals are crucial for understanding human population genetics, it is no less crucial that we should be fully aware of the uncertain nature of the prehistoric facts that linguistic data can be used to reconstruct.

Diamond reports Bellwood and Renfrew's argument that major demographic upheavals ('steamrollers') at different times in the past 10,000 years, resulting from domestication of certain species of plants and animals, have erased "the products of previous tens of thousands of years of language evolution" in some parts of the world (for example, Europe) more strongly than in others (for example, New Guinea and 'native' California). But there is no generally accepted theory of language diversification $^{2,3}$; indeed, Renfrew and Bellwood's views are strongly contested ${ }^{4-6}$. Measuring the degree of isolation between human groups and estimating the length of time since their presumed separation (isolation) does not adequately predict either number of languages per unit area or their taxonomic (historical) diversity ${ }^{7}$.

These are a few of the reasons why we are reluctant to agree that modern New Guinea or aboriginal California can be taken as models for other places and times in history. Nobody knows what the linguistic diversity of Europe at the end of the Pleistocene was like and one can only guess at the linguistic situation in Europe even as late as the early Bronze Age, in the second millennium BC. Were one to accept Diamond's metaphor of the language steamroller as a heuristic device and his argument that speakers of (an unknown number of) early Indo-European languages moved "as a steamroller" over Europe, there is no way to tell whether these hypothesized migrants (or just the Indo-European language) had to flatten a sharply dissected linguistic landscape or rolled over a basically level field.

The solution to the mystery of historical linguistics will come only with better historical data and better sociolinguistic models ${ }^{8}$.

\section{John Edward Terrell}

New Guinea Research Program, The Field Museum,

Chicago, Illinois 60605, USA

e-mail: terrell@fmppr.fmnh.org

John Hines

School of History and Archaeology,

University of Wales, Cardiff CF1 3XU, UK

Terry L. Hunt

Department of Anthropology,
University of Hawaii at Manoa, Honolulu,

Hawaii 96822, USA

Chapurukha Kusimba

Department of Anthropology, The Field Museum, Chicago, Illinois 60605, USA

Carl Lipo

Department of Anthropology,

University of Washington, Seattle,

Washington 98195, USA

The spread of Indo-European languages is often exclusively attributed to agricultural progress, whereas an alternative hypothesis, the domestication of the horse for warfare, tends to be ignored. Only a few years ago a good case was made for the steamrollering of undefended Old European cultures ${ }^{9}$ and languages by the first 'armoured vehicle', the horse ${ }^{10,11}$, whose breaking to the bit coincided with proto-Indo-European languages geographically (Ukraine) and in time (at least 4,000 BC).

In anthropology we are witnessing the resurrection of hypotheses depicting our ancestors as fierce big-game killers, even cannibals $^{12}$, at the expense of more politically correct views of noble vegetarians or, at worst, scavengers. Could the spread of language be another aspect to this argument? Is the idea of peaceful, egalitarian cultures subjugated by male barbarians less palatable than their displacement by a superior agricultural technology?

Why were California and New Guinea spared a linguistic takeover? Could it be because the horse never got there? Perhaps the 'aggression' and 'technology' mechanisms for competitive exclusion of cultures are not incompatible, but rather occurred in different mixes, with the sword leading in Indo-Europe and the plough in Africa.

Wolfgang E. Sterrer

Bermuda Natural History Museum, PO Box FL

145, Flatts FLBX, Bermuda

e-mail:wsterrer@bbsr.edu

Diamond replies - By 'language steamroller' is meant the massive replacement of a region's languages by languages from the outside. Some military, technological, political or demographic advantage enables outsiders to impose their language or even to conquer or replace the original inhabitants. Terrell et al. question whether the suggested 'steamrollers' could be real, whereas Sterrer discusses their interpretation.

The evidence for steamrollers is overwhelming and familiar. In modern times, European overseas expansion resulted in English, Spanish, French and Portuguese replacing thousands of native languages of other continents. (Why else would this issue of Nature be printed for North American readers in English, rather than in a Native American language?) Abundant linguistic evidence testifies to many equally massive earlier replacements, of which the Bantu expansion over sub-Saharan Africa and the Austronesian expansion over the tropical Pacific are particularly well attested by independent archaeological and genetic evidence.

In western Europe, all of the many modern languages except Basque belong to the Indo-European language family, which diversified during the past 5,000-10,000 years from an ancestral language spoken somewhere in western Asia. Do Terrell et al. believe all Europeans spoke a single tongue, Basque, until a few thousand years ago? In fact, preserved Etruscan and Iberian writing from Roman times, and residues of nonIndo-European words swept up into existing European languages, testify to the existence of many other non-Indo-European languages supplanted by Indo-European. Whether former language diversity in Europe was higher or lower than in modern New Guinea and aboriginal California is beside the point; the supplanting of that diversity still cries out for explanation.

As for the mechanism of that supplanting, Sterrer is correct: there are various types of advantage that can enable one group of people to conquer (or to impose their language on) another. Most known steamrollers can ultimately be related in some way to food production, because it is the agent that has produced the biggest effects on human population numbers and human societies in the past 10,000 years.

There is a long-standing and unresolved debate over whether the Indo-European steamroller was driven by the demographic advantages that West Asian food producers gained 9,000 years ago over Europe's original hunter/gatherer population, or whether the domestication of the horse (the jeep and Sherman tank of ancient warfare) became crucial after 6,000 years ago. As Sterrer notes, Gimbutas ${ }^{13}$ amassed strong arguments for the latter view, but Renfrew ${ }^{14}$ has also made a strong case for the former view. This is just one example of the many fascinating problems posed by the language steamrollers that jump out at us from language maps of the world.

\section{Jared Diamond}

Physiology Department, UCLA Medical School, Los Angeles, California 90095-1751, USA

\footnotetext{
1. Diamond, J. M. Nature 389, 544-546 (1997)

2. Hill, J. H. Languages on the Land: Toward an Anthropological Dialectology (Dept. of Anthropology, Indiana Univ., 1996). 3. Nettle, D. J. Anthrop. Archaeol. 15, 238-403 (1996).

4. Hines, J. Archaeol. Pol. 34, 183-197 (1997).

5. Zvelebil, M. J. Eur. Archaeol. 3, 33-70 (1995).

6. Terrell, J. \& Welsch, R. L. Antiquity 71, 548-572 (1997).

7. Swadesh, M. in The Origin and Diversification of Language (ed. Sherzer, J.) 8-42 (Aldine-Atherton, Chicago, 1971).

8. Terrell, J. et al. Curr. Anthropol. 38, 155-195 (1997).

9. Gimbutas, M. The Civilization of the Goddess (Harper Collins, San Francisco, 1991).

10. Anthony, D. et al. Sci. Am. 295(6), 44-48A (1991).

11. Diamond, J. M. Nature 350, 275-276 (1991).

12. Gibbons, A. Science 277, 635-637 (1997).

13. Gimbutas, M. The Balts (Praeger, New York, 1963).

14. Renfrew, C. Archaeology and Language: the Puzzle of IndoEuropean Origins (Cape, London, 1987).
} 